\title{
Principios constitucionales que rigen el sistema tributario
}

\author{
César Augusto Romero-Molina ${ }^{\star}$, Yenny Cristina Grass-Suárez ${ }^{\star *}$, Ximena Cristina García-Caicedo $^{\star \star \star}$
}

* Posdoctorado de la Universidad de Castilla-La Mancha. Doctor en Derecho de la Universidad San Pablo-CEu. Director del Centro de Investigaciones Sociojurídicas (CIs) de la Facultad de Derecho de la Universidad Cooperativa de Colombia, sede Bucaramanga, Colombia.

Correo electrónico:

cesaraugusto.romero@gmail.com

** Abogada de la Universidad Cooperativa de Colombia, sede Bucaramanga. Contadora Pública de la Universidad Santo Tomás, Colombia. Abogada y contadora independiente.

Correo electrónico: cristinagrass@hotmail.com

*** Abogada de la Universidad Cooperativa de Colombia, sede Bucaramanga. Abogada independiente.

Correo electrónico: jaxi1001@hotmail.com

Recibido: 14 de diciembre del 2012 Aprobado: 17 de abril del 2013

Cómo citar este artículo:

César Augusto Romero-Molina, Yenny Cristina Grass-Suárez \& Ximena Cristina GarcíaCaicedo. Principios constitucionales que rigen el sistema tributario. DIxI. Junio 2013. At. 67.

\section{Resumen}

La intención de este artículo es determinar cuáles son los principios que rigen el sistema tributario, analizando sus límites y alcances en la aplicación de las normas tributarias, de acuerdo con lo establecido por la jurisprudencia de las altas cortes. La finalidad consiste en determinar el límite a la arbitrariedad impositiva que tiene el Estado y regular las relaciones con los individuos que la componen. Cada uno de estos principios (legalidad, igualdad, eficiencia, equidad, progresividad, irretroactividad, unidad de materia y capacidad contributiva), regulan una serie de valores que permiten que el Estado y los individuos se relacionen solidariamente para cubrir los servicios básicos necesarios.

Palabras clave: Constitución Política, jurisprudencia, principios constitucionales, tributo.

\section{Constitutional Principles Governing the Tax System}

\section{Abstract}

The intention of this article is to identify principles governing the tax system, analyzing its limits and scope in the application of tax regulations, pursuant to high court rulings. The purpose is to determine the limit on the arbitrary power of the State to tax and regulate its relationship with the individuals of whom it is composed. Each of these principles (legality, equality, efficiency, fairness, progressivity, retroactivity, unity of matter and ability to pay) regulate a number of values that allow the state and individuals to relate jointly to cover basic necessary services.

Keywords: Constitution, jurisprudence, constitutional principles, taxes.

\section{PRINCíPIOS CONSTITUCIONAIS QUE REGEM O SISTEMA TRIBUTÁRIO}

\section{Resumo}

A intenção deste artigo é determinar quais são os princípios que regem o sistema tributário e analisar seus limites e alcances na aplicação das normas tributárias, de acordo com o estabelecido pela jurisprudência das altas cortes. A finalidade consiste em determinar o limite para a arbitrariedade impositiva que o Estado tem e regular as relações com os indivíduos que a compõem. Cada um destes princípios (legalidade, igualdade, eficiência, equidade, progressividade, irretroatividade, unidade de matéria e capacidade contributiva) regula uma série de valores que permitem que o Estado e os indivíduos se relacionem solidariamente para cobrir os serviços básicos necessários.

Palavras-chave: Constituição Política, jurisprudência, princípios constitucionais, tributo. 


\section{INTRODUCCIÓN}

Para interpretar los principios que rigen el sistema tributario en Colombia debemos enmarcarlos dentro de la acepción de nuestra Carta Política de 1991, en su artículo $1^{\circ}$, en el que contempla a Colombia como un Estado Social de Derecho. Esta concepción está encaminada de acuerdo con el concepto de justicia social en el que se introduce al ser humano como el eje central de la política social y económica del país, y que consiste en brindar seguridad, confianza e igualdad a todos sus conglomerados.

La jurisprudencia constitucional ha manifestado la Constitución de 1991, en la cual se estableció a Colombia como Estado Social de Derecho, y asimismo establece como función de las autoridades hacer prevalecer los principios fundamentales con el fin de que puedan dar cumplimiento a los fines contemplados en el artículo 1 Superior. En Sentencia C-445 de 1995 afirma:

Estado Social de Derecho. Principios tributarios. La función de las autoridades es no sólo proclamar los derechos fundamentales sino, $y$ tal vez sobre todo, hacer efectivos esos derechos en la vida cotidiana de las personas. Sólo de esa manera se puede lograr que la igualdad entre las personas sea real y efectiva. Ahora bien, para poder desarrollar sus actividades, cumplir sus fines y realizar los valores que encarna el ordenamiento constitucional, las autoridades públicas requieren permanentemente de recursos, puesto que no sólo ciertas necesidades sólo pueden ser satisfechas mediante prestaciones públicas sino que, además, muchos de los derechos fundamentales que en apariencia implican un deber estatal de simple abstención - los llamados derechos humanos de primera generación o derechos civiles y políticos-en la práctica requieren también intervenciones constantes del Estado. En efecto, el goce de estos derechos por las personas requiere, por ejemplo, una eficaz administración de justicia y una diligente labor de la Fuerza Pública, a fin de que se garantice una convivencia pacífica entre los colombianos. ${ }^{1}$

Esta acepción va unida a los principios fundamentales inherentes a la persona humana, pues nace con ellos y por tanto no son objeto de negociación por parte del Estado, sino que, por el contrario, en caso de transgresión o violación, el Estado debe poner en movimiento toda su esfera política para velar por su protección

1 Ver Corte Constitucional de Colombia. Sentencia C-445 de 1995. (M.P. Alejandro Martínez Caballero: Octubre 4 de 1995). y por el respeto al valor intrínseco de la vida humana como objeto irremplazable e invaluable de cualquier cosa material. Estos valores regulan la relación entre el Estado y sus individuos, los cuales agrupan la dignidad humana, el trabajo, la solidaridad y la igualdad, contemplados en los artículos 1 y 13 , respectivamente.

Estos valores constitucionales regulan el acceso de todas las personas en igualdad de condiciones a los servicios básicos, pero para obtener estos servicios debe existir una relación de solidaridad entre el ciudadano y el Estado, derivándose unos principios fundamentales que regulan el sistema tributario como son la legalidad, igualdad, equidad, eficiencia, progresividad, irretroactividad, unidad de materia y capacidad contributiva, contenidos en los artículos 13, 58, 338, y 363 de nuestra C.P.

La autonomía territorial emana del principio democrático, entre otras razones, porque las autoridades territoriales se constituyen a partir del voto directo y universal de las comunidades. En este sentido, la descentralización y la autonomía guardan estrecha relación con el principio de eficiencia de la administración pública. Por ello, la Constitución define el municipio como entidad fundamental del sistema político administrativo del Estado, al ser la organización local de mayor cercanía y conexión con la población (c.P. art. 311).

\section{PRINCIPIO DE LEGALIDAD TRIBUTARIA}

Este principio está concebido bajo un aforismo penal muy antiguo que contempla que "no hay tributo sin ley que lo establezca", 2 o más conocido como "nullum tributum sine lege", ${ }^{3}$ esto quiere decir que todo tribu-

\footnotetext{
2 Ver Ramón Valdés Costa. Instituciones de derecho tributario. Pág. 121. Lexis Nexis Depalma. (2004).

3 Ver Hugo Mario Sierra \& Alejandro Salvador Cántaro. Lecciones de derecho penal. Parte general. Pág. 121. Universidad Nacional del Sur. (2005). "[...] o sea, como ya se señaló, la única fuente de conocimiento del derecho penal es la ley. Nuestra Constitución establece en su art. 18 que "ningún habitante de la Nación puede ser penado sin juicio previo fundado en ley anterior al hecho del proceso [...]", consagrando así el llamado principio de legalidad penal, que ya estaba previsto en la Constitución de los Estados Unidos y en la Declaración de los Derechos del Hombre y del Ciudadano de 1789. Sus alcances fueron dados por von Feuerbach en su famosa formulación "nullum crime sine lege" o en la ampliada "nulla Poena sine lege, nulla poena sine crimine, nullum crimen sine poena legale".

El principio de legalidad es una característica distintiva de las constituciones modernas de los países civilizados. Es la máxima garantía del derecho penal liberal en cuanto constituye la más poderosa limitación del poder punitivo. La exigencia de legalidad supone que la ley penal debe ser previa, escrita, formal y estricta".
} 
to debe estar contemplado expresamente por una ley, con el fin de generar seguridad jurídica al contribuyente, y que el Congreso, por mandato Constitucional (artículo 150 num. 12 y 338 c.P.) está facultado para crear, modificar, suprimir o aumentar los tributos. La Corte Constitucional, en Sentencia C-776 del 2003, aduce que "[...] el Congreso de la República goza de la más amplia discrecionalidad, desde luego siempre que la aplique razonablemente y sujeto a la Constitución, tanto para crear como para modificar, aumentar, disminuir y suprimir tributos".

Pero la competencia del legislador no se limita únicamente a imponer los tributos, sino que, por el contrario, comprende redistribuir esos recursos de manera equitativa e igualitaria a toda la sociedad, con el propósito de que sean realizados todos los fines esenciales del Estado ${ }^{4}$ en aumentar la capacidad de prestación de esos servicios.

Entonces, la facultad legislativa para definir el ámbito de la autonomía territorial está limitada tanto por la imposición constitucional que salvaguarda la autonomía territorial (C.P., art. $1^{\circ}$ ) como por los principios de fundamentalidad del municipio y los de coordinación, concurrencia y subsidiariedad (C.P., arts. 288 y 311 ).

La jurisprudencia constitucional, en Sentencia C-1383 del 2003 ha sostenido que:

[...] el empleo de la facultad reconocida a las autoridades para la creación de cargas impositivas, debe respetar el principio de reserva legal que, expresado en el aforismo "nullum tributum sine lege", señalando la necesidad de un acto del legislador para la creación de gravámenes, como el respeto al supuesto político de la representación, por virtud del cual, la creación de impuestos va de la mano del consentimiento - directo o indirecto- de la colectividad, que reconoce por esta vía una manera eficaz y necesaria para transferir los recursos que necesita el Estado en cumplimiento de su función. ${ }^{5}$

Lo anterior nos permite establecer que el tributo es un impuesto de creación legal y que, por tanto, no existe ninguna disposición constitucional en la que se señale quiénes deben ser sus sujetos pasivos, de tal manera

4 Ver Enrique Evans de la Cuadra. Los tributos ante la Constitución. Pág. 66. Jurídica de Chile. (1997). “[...] la obligación de pagar tributos reconoce, dentro de la organización del Estado de Derecho, como fuente exclusiva a la ley. Constituye ése un aspecto principal de derecho tributario, el cual se ha sintetizado en la expresión "no hay tributo sin ley que lo establezca”.

5 Ver Corte Constitucional de Colombia. Sentencia C-1383 del 2003. (M.P. Clara Inés Vargas H: Abril 16 del 2003). que la ley debe contener ese elemento del tributo; significa que le compete al legislador, según el artículo 338 de la Constitución, fijar los sujetos activos y pasivos, los hechos y las bases gravables y las tarifas de los impuestos. La materialidad de los impuestos radica en el contenido de los elementos esenciales dentro de la norma. ${ }^{6}$

De lo anteriormente descrito surge este interrogante: si dentro de la norma tributaria no se establecen los elementos, ¿a quién le corresponde establecerlos?

La Constitución de 1991, en su artículo 338, le da competencia al Congreso de la República para crear la norma tributaria y dentro de ella establecer los elementos esenciales del tributo, pero en caso de no establecerlos, los entes territoriales - basados en el principio de autonomía territorial- pueden establecer los elementos del tributo, dado que no sólo la ley los establece, sino que también los pueden fijar las ordenanzas departamentales y los acuerdos municipales, sin restarle la competencia que tiene el Congreso, que es el único facultado para crear la norma tributaria.

Como lo manifiesta García Belsunce (citado por Héctor Villegas, $2001^{7}$ ), el principio de legalidad tributaria

[...] constituye una garantía esencial en el derecho constitucional tributario, en cuya virtud se requiere que todo tributo sea sancionado por una ley, entendida ésta como la disposición que emana del órgano constitucional que tiene la potestad legislativa conforme a los procedimientos establecidos por la Constitución para la sanción de las leyes, y que contiene una norma jurídica.

La finalidad pretendida a través de este principio es proteger la seguridad jurídica y limitar el poder impositivo del Estado, permitiendo que el Congreso de la República sea el único ente autorizado para crear, modificar o derogar las normas. Sin embargo, el art. 338 C.N. extiende dichas facultades a las asambleas departamentales y a los concejos municipales a través de las ordenanzas y los acuerdos para que establezcan los elementos del tributo con el fin de evitar arbitrariedades y limitar el poder por parte de la administración.

\footnotetext{
6 Ver Antonio Berliri. Apuntes sobre el fundamento y contenido del Art. 23 de la Constitución. Págs. 139-233. (1961). “[...] no es necesario que la ley formal regule todos los elementos del impuesto, pudiendo, por el contrario, encomendar al reglamento la especificación de algunos de esos elementos".

7 Héctor Villegas. Curso de finanzas, derecho financiero y tributario. Pág. 190. Ediciones Depalma. (2001).
} 
El principio de legalidad debe tener unos alcances significativos frente a la norma tributaria, que se definen de la siguiente manera:

1. La norma tributaria rige igual para todos los tributos tales como impuestos, tasas y contribuciones especiales.

2. El Ejecutivo no tiene facultades legislativas por cuanto violaría el principio de legalidad consagrado en el art. 150 de la Constitución Nacional.

3. No se puede crear una norma tributaria con efectos retroactivos, ya que le generaría inseguridad jurídi$\mathrm{ca}$ al contribuyente.

De lo expuesto anteriormente podemos concluir que la jurisprudencia constitucional no ha sido muy clara en determinar quiénes son los encargados de establecer los elementos de la norma tributaria, sino que, por el contrario, al leer desprevenidamente el artículo 338 de la Constitución Política, podemos comprender que ni a las Asamblea Departamentales ni a los Concejos Municipales se les conceden competencias legislativas para crear los elementos de la norma tributaria, como lo señala el doctor César Romero cuando afirma que:

[...] la Corte Constitucional ha pasado por tres etapas o criterios frente a la interpretación de los elementos de la ley que crea lo tributos territoriales:

a. El primero, manifestando que todos los elementos de la obligación tributaria territorial debían fijarse por el legislador...

b. El segundo, permitiendo que la ley de autorizaciones cree el tributo y las asambleas y concejos fijen los demás elementos del mismo. Se hace una distinción entre la ley creadora y ley de autorizaciones del tributo territorial: la primera determina todos los elementos de la obligación tributaria y en la segunda el legislador debe señalar ciertas regulaciones o fijar criterios generales para que los entes territoriales correspondientes (asambleas y concejos) ejerzan sus competencias autonómicas en materia tributaria...

c. El tercero, exigiéndole al legislador los dos parámetros básicos a saber: la autorización y el hecho imponible o hecho generador.

"De las fases presentadas sobre las diferentes interpretaciones ejercidas por la Corte Constitucional es posible concluir que las normas constitucionales no son claras al respecto del ejercicio de las competencias por los entes territoriales en materia tributaria, ya que una lectura desprevenida del artículo 338 Superior no permite deducir posibilidad alguna para que las asambleas y concejos creen tributo. Su atribución constitucional se reduce a establecerlos o ignorarlos en su jurisdicción, conservando así su competencia derivada. De lo contrario, se podría concluir que su competencia es originaria y entonces sería inocua la atribución del Congreso de crear las leyes tributarias, dada en el numeral 12 del artículo 150 de la Carta Magna. ${ }^{8}$

\section{PRINCIPIOS DE EQUIDAD, EFICIENCIA Y PROGRESIVIDAD DEL TRIBUTO}

Estos principios tributarios están contemplados en el artículo 363 Superior "El sistema tributario se funda en los principios de equidad, eficiencia y progresividad". Lo que se busca principalmente con estos principios es la justicia, y evitar que la norma tributaria sea arbitraria o afecte derechos fundamentales, y que, por el contrario, sea equilibrada, eficiente en la prestación de los servicios, progresiva y que vaya acorde con los cambios de las nuevas tecnologías; que tanto el Estado como la población progresen económica, social y políticamente.

La Corte Constitucional de Colombia, en Sentencia C-643 del 2002, ${ }^{9}$ estableció que estos principios constitucionales: "[...] constituyen los parámetros para determinar la legitimidad del sistema tributario y, como ha tenido oportunidad de precisarlo esta Corporación, se predican del sistema en su conjunto y no de un impuesto en particular".

Estos principios tributarios consagran el límite impuesto al Estado en relación con la actuación tributaria, que se encuentra relacionada con la obligación de quien tributa y de los derechos que le asisten frente al Estado y de los compromisos que debe cumplir. El Estado debe velar por que todos los obligados cumplan sus compromisos, pero también que esos fondos sean repartidos equitativamente a toda la población.

La esencia de estos principios consiste en que los impuestos sean justos y equilibrados; que el sujeto pasivo de la obligación no sea desmejorado en su condición, pues conllevaría una desigualdad, pondría a la administración en un grado de superioridad, causando

\footnotetext{
8 Ver César Romero Molina. El principio de legalidad tributaria en la expedición de normas territoriales. Revista DIXI. 2010. At. 115-121.

9 Ver Corte Constitucional de Colombia. Sentencia C-643 del 2002 (M.P. Jaime Córdoba Triviño: Agosto 13 del 2002).
} 
con ello arbitrariedad y atesoramiento en detrimento del contribuyente.

La jurisprudencia de la Corte Constitucional, en Sentencia C-734 del 2002, ${ }^{10}$ ha explicado que la equidad del sistema tributario:

[...] es un criterio con base en el cual se pondera la distribución de las cargas y de los beneficios o la imposición de gravámenes entre los contribuyentes para evitar que haya cargas excesivas o beneficios exagerados. Una carga es excesiva o un beneficio es exagerado cuando no consulta la capacidad económica de los sujetos pasivos en razón a la naturaleza y fines del impuesto en cuestión.

Es así como en diferentes oportunidades la Corte ha manifestado que no sólo se debe mirar el límite basado en la capacidad contributiva, sino que, por el contrario, debe basarse en los principios en que está consagrado el Estado Social de Derecho.

Con respecto al principio de progresividad, la Corte, en Sentencia C-173 del 2010 ha manifestado que:

[...] hace referencia al reparto de la carga tributaria entre los diferentes obligados a su pago, según la capacidad contributiva de la que disponen, es decir, es un criterio de análisis de la proporción del aporte total de cada contribuyente en relación con su capacidad contributiva. En este orden de ideas, es neutro el sistema que conserva las diferencias relativas entre los aportantes de mayor y de menor capacidad contributiva; es progresivo el que las reduce; y es regresivo el que las aumenta. ${ }^{11}$

Al respecto, la Corte Constitucional ha manifestado que busca evitar que el monto a cancelar sea exagerado y supere la capacidad contributiva del que está obligado a realizarla; no solo se debe tener en cuenta el límite basado en la capacidad contributiva sino que, por el contrario, debe basarse en los principios en que está consagrado el Estado Social de Derecho.

El principio de equidad tributaria busca hacer equitativa la carga tributaria entre todos los obligados en relación con la capacidad contributiva, buscando diversificar la diferencia entre los aportantes. ${ }^{12}$

10 Ver Corte Constitucional de Colombia. Sentencia C-734 del 2002 (M.P. Manuel José Cepeda Espinoza: Septiembre 10 del 2002).

11 Ver Corte Constitucional de Colombia. Sentencia C-173 del 2010. (M.P. Clara Inés Vargas H: Abril 16 del 2010).

12 Ver Juan Rafael Bravo Arteaga. Derecho tributario: escritos y reflexiones. Pág. 156. Universidad del Rosario. (2008). “[...] se ocupa de regular las relaciones, generalmente dinerarias, que tienen los particulares con el Estado, por la virtud de la realización de determinados actos o hechos
En la Sentencia C-173 del 2010, la Honorable Corte Constitucional aduce que la obligación tributaria del sujeto pasivo está relacionada con su capacidad de pago respecto de los impuestos directos e indirectos, pues en los impuestos directos se identifica al contribuyente porque se establece su capacidad de pago por medio de informaciones aportadas por él mismo, tales como el impuesto de renta y patrimonio, y en los impuestos indirectos la capacidad de pago del obligado se mide de acuerdo con su consumo, la compra de artículos suntuosos, que se adquieren dependiendo de la capacidad económica que se posea.

\section{Principio de progresividad tributaria - Contenido} La jurisprudencia ha aceptado que el principio constitucional de progresividad tributaria se hace efectivo de manera más concreta y efectiva en materia de impuestos directos, mediante el recurso al establecimiento de tarifas progresivas respecto de un mismo gravamen, según los niveles de renta o patrimonio del contribuyente. En cambio, en materia de impuestos indirectos, como el IVA, "la progresividad es más difusa, y parte de la presunción relativa a la mayor capacidad adquisitiva de aquellas personas que gastan en bienes o servicios más costosos y menos relacionados con la satisfacción de necesidades básicas, los cuales son gravados con tarifas más altas". Es decir, el principio constitucional de progresividad tributaria, en relación con los impuestos indirectos como el IVA, sólo puede hacerse efectivo cuando el gravamen recae sobre el consumo de bienes que no son considerados básicos, cometido que se logra mediante la imposición de tarifas cada vez más altas, en cuanto menos básico o más suntuario es el consumo del bien o servicio en cuestión. De donde se deduce que las tarifas más altas del IVA, cuando hay tarifas diferenciales, en principio deben reservarse para productos que no puedan clasificarse como de consumo básico. ${ }^{13}$

Para Martin Delgado, la progresividad ha sido catalogada como una característica esencial del sistema tributario, por cuanto al aumentar la riqueza del contribuyente, aumentan las arcas del Estado, ${ }^{14}$ teniéndola como un complemento de la capacidad económica que

jurídicos establecidos en la ley como presupuestos del nacimiento de la obligación. Como consecuencia de las obligaciones del particular, existe correlativamente un derecho del Estado. La filosofía, desde los tiempos de Grecia, ha distinguido entre la justicia conmutativa y la distributiva. La primera se refiere a las cosas y la segunda a las personas.

13 Ver id. Cita 11.

14 Ver Marco Antonio Méndez Moreno. Derecho financiero y tributario. Parte general. Lecciones de cátedra. Pág. 85. Lex Nova. (2008). 
sirve como base en la realización de un sistema justo y sólo es aplicable a los impuestos indirectos. ${ }^{15}$

Y por último, el principio de eficiencia radica en el mecanismo que emplea el Estado colombiano para lograr un mayor recaudo, sin desmejorar la condición de vida de sus habitantes, y a ello hacen referencia las Sentencias C-419 de $1995^{16}$ y C-261 del $2002{ }^{17}$ en las que se considera el principio de eficiencia como:

[...] recurso técnico del sistema tributario dirigido a lograr el mayor recaudo de tributos con un menor costo de operación; pero de otro lado, se valora como principio tributario que guía al legislador para conseguir que la imposición acarree el menor costo social para el contribuyente en el cumplimiento de su deber fiscal (gastos para llevar a cabo el pago del tributo).

La única finalidad consiste en lograr el beneficio económico y social sin desmejorar al sujeto pasivo de la obligación, y hallar alternativas para el beneficio colectivo mejorando la cobertura de los servicios esenciales para aquellos, y buscando que se tribute en igualdad de condiciones mediante tratamientos diferenciados en el recaudo del tributo; la jurisprudencia constitucional en Sentencia C-664 del 2009 manifiesta que:

El principio de equidad tributaria es la manifestación del derecho fundamental de igualdad en esa materia y por ello proscribe formulaciones legales que establezcan tratamientos tributarios diferenciados injustificados tanto por desconocer el mandato de igual regulación legal cuando no hay razones para un tratamiento desigual, como por desconocer el mandato de regulación diferenciada cuando no hay razones para un tratamiento igual. La Corte también ha diferenciado entre la equidad vertical y la equidad horizontal y para la configuración teórica de esos conceptos ha recurrido al principio de progresividad. Así, en virtud de la equidad horizontal, las personas con capacidad económica igual deben contribuir de igual manera mientras que, de acuerdo con la equidad vertical, las personas con mayor capacidad económica deben contribuir en mayor medida. ${ }^{18}$

15 Ver Ángeles García Frías. La financiación territorial mediante recargos: un análisis jurídico. Pág. 151. Universidad de Salamanca. (1994).

16 Ver Corte Constitucional de Colombia. Sentencia C-419 de 1995 (M.P. Antonio Barrera Carbonell: Septiembre 21 de 1995).

17 Ver Corte Constitucional de Colombia. Sentencia C-261 del 2002 (M.P. Clara Inés Vargas Hernández: 16 de Abril del 2002).

18 Ver Corte Constitucional de Colombia. Sentencia C-664 del 2009. (M.P. Clara Inés Vargas H: Abril 16 del 2009.

\section{PRINCIPIO DE IGUALDAD TRIBUTARIA}

Este principio considera la diferencia social que existe entre los habitantes del Estado colombiano; va de la mano con los principios de equidad, progresividad y capacidad de pago; busca poner un límite al poder del Estado ${ }^{19} \mathrm{y}$ así evitar arbitrariedades, resulta ser un complemento de la capacidad económica ${ }^{20}$ que tienen los ciudadanos para contribuir con el Estado, está ligado a los principios y valores en que debe caminar el Estado con el fin de evidenciar la justicia del bien común, asimismo, como la base jurídica de la contribución a los fines del Estado. ${ }^{21}$

El principio de igualdad exige el mismo trato tanto para los entes como para los hechos que se encuentran amparados bajo un mismo supuesto, buscando con ello brindarle al contribuyente el mismo trato bajo las mismas condiciones, sin discriminación alguna.

Para Juan Martin Queralt, desde el punto de vista tributario, el principio de igualdad

[...] se traduce en forma de capacidad contributiva, en el sentido de que situaciones económicamente iguales sean tratadas de la misma manera, puesto que la capacidad económica que se pone de relieve es la misma, sin embargo, ello no significa que el principio de igualdad tributaria agote el contenido con el de capacidad económica (sTC g/1986, de 21 enero [RT1986, 81); entre otros motivos porque, como señaló el TC, las discriminaciones no son arbitrarias cuando se establecen en función de un criterio amparado por el ordenamiento, aun cuando pertenezca a otra rama jurídica. ${ }^{22}$

Lo anterior considera que sólo pueden introducirse discriminaciones en forma material en la obligación tributaria de manera justa y equitativa, es decir, que

19 Ver Lejeune Valcárcel. Seis estudios de derecho constitucional e internacional tributario. Aproximación al Principio de igualdad tributaria. Pág. 121. Edersa. (1980). "[...] en el vértice, pues, del ordenamiento jurídico, una sola justicia y un solo principio básico, superándose de esta forma esa no deseable situación de compartimentos estancos, de "justicias" y "principios" que podrían fácilmente detectarse de adoptar otras posiciones metodológicas, lo que nada o poco aprovecharía para una comprensión global del ordenamiento jurídico y del papel queéste ha de desarrollar al servicio del modelo de sociedad que se dibuja en la Constitución".

20 Ver Isaac Merino Jara. Derecho financiero y tributario. Parte general. Lecciones adaptadas al EeEs. Pág. 108. Tecnos. (2011).

21 Ver Cruz de Quiñónez 1. Lecciones de derecho tributario inspiradas por un maestro. Tomo I. Liber Amicorum en homenaje a don Eusebio González García. Pág. 162. Universidad del Rosario. (2010).

22 Ver Juan Martín Queralt, Carmelo Lozano Serrano \& Francisco Poveda Blanco. Derecho tributario. Pág. 58. Thomson Reuters Aranzadi. (2011). 
cuando se hallen bajo el mismo hecho y se aplicase un beneficio debe ser de manera general, sin dilaciones, teniendo en cuenta la capacidad económica del obligado.

Desde el punto de vista del principio de legalidad, deben aplicarse los criterios de razonabilidad basados en la ley y en la actualidad social, tal y como lo manifiesta Linares (citado por Catalina García 1996):

la garantía del debido proceso sustantivo se tipifica por su exigencia de razonabilidad ponderativa y no de la selección, sin perjuicio de lo cual en la obra citada en este trabajo también aborda este último aspecto, habida cuenta del parentesco entre ambas. La razonabilidad de la selección se refiere a la valoración de ciertas circunstancias del caso para elegir unas y eliminar otras en la determinación del hecho antecedente al cual se imputa una consecuente (prestación o sanción). Esta especie se halla emparentada con el principio de igualdad, de larga evolución en cuanto a su significación por parte de la Corte Suprema argentina. En efecto: en 1875 sostuvo que la igualdad consiste en que "no se establezcan excepciones o privilegios que excluyan a unos de lo que se concede a otros en iguales circunstancias, de donde se sigue forzosamente, que la verdadera igualdad consiste en aplicar en los casos ocurrentes la ley según las diferencias constitutivas de ellos, y que cualquiera otra inteligencia o acepción de este derecho es contraria a su propia naturaleza e interés social".23

Según Sentencia C-183 de 1998, la jurisprudencia colombiana ha destacado en varias oportunidades que:

[...] el principio de legalidad del tributo, de profunda raigambre democrática, el principio de igualdad constituye claro límite formal y material del poder tributario estatal y, por consiguiente, las reglas que en él se inspiran se orientan decididamente a poner coto a la arbitrariedad y a la desmesura. No se trata de establecer una igualdad aritmética. La tributación tiene que reparar en las diferencias de renta y riqueza existentes en la sociedad, de modo que el deber fiscal, expresión de la solidaridad social, tome en cuenta la capacidad contributiva de los sujetos y grupos y, conforme a ella, determine la carga fiscal, la que ha de asignar con criterios de progresividad, a fin de alcanzar grados cada vez mayores de redistribución del ingreso nacional. ${ }^{24}$

\footnotetext{
23 Ver Catalina García Vizcaíno. Derecho tributario, consideraciones económicas y jurídicas. Edición de Palma. (1996).

24 Ver Corte Constitucional de Colombia. Sentencia C-183 de 1998. (M.P. Clara Inés Vargas H: Abril 16 de 1998).
}

Este principio ha sido inspiración del preámbulo de nuestra Carta Magna, en la que reza lo siguiente:

[...] en ejercicio de su poder soberano, representado por sus delegatarios a la Asamblea Nacional Constituyente, invocando la protección de Dios, y con el fin de fortalecer la unidad de la Nación y asegurar a sus integrantes la vida, la convivencia, el trabajo, la justicia, la igualdad $[\ldots]$.

Destaca la importancia que tienen los cuerpos colegiados y su labor por propender la protección a los contribuyentes por medio de leyes que le permitan frenar el poder del Estado en materia tributaria, basados en principios constitucionales como los de igualdad, equidad y capacidad de pago.

Igualmente, en Sentencia C-183 de 1998, la Corte destaca que:

La igualdad impone la necesidad de acatar como regla tributaria básica la generalidad del tributo. Si al margen de los contribuyentes se coloca a aquellas personas que carecen de capacidad contributiva, todos los demás ciudadanos, según su poder económico y en los términos de la ley, quedan sujetos al mismo deber de concurrir al levantamiento de las cargas públicas. El privilegio en la ley y en la aplicación de la ley, resulta definitivamente proscrito, pues el poder tributario se fundamenta en la justicia y en la equidad.

La generalidad del tributo, aparte del componente subjetivo que comporta - el universo de los obligados por el tributo ha de comprender sin excepciones a todas las personas que tengan capacidad contributiva-, tiene uno de naturaleza objetiva. Si el legislador grava con un impuesto un hecho, acto o negocio, por ser precisamente indicativos de riqueza actual o potencial, no puede dejar de hacerlo ante situaciones semejantes o equiparables, salvo que militen razones poderosas de política fiscal o fines extrafiscales relevantes, siempre que, en este último caso, los mismos estén al servicio de bienes protegidos por la Constitución o de metas ordenadas por ella.

\section{PRINCIPIO DE CAPACIDAD CONTRIBUTIVA}

Este principio destaca la importancia en la justicia del sistema tributario ${ }^{25}$ que dentro de un Estado social

25 Ver Carlos Palado Taboada. Apogeo y crisis del Principio de capacidad contributiva. Estudios homenaje al maestro Federico de Casto. Vol. 
de derecho tienen las personas que no poseen la capacidad económica y deben ser protegidas sin discriminación alguna, tratadas con dignidad y respeto sin imponerles cargas tributarias que no puedan cumplir.

Obligar a quienes carecen de dicha capacidad a soportar estas cargas públicas impositivas, resulta contrario al verdadero sentido del Estado Social de Derecho, que busca proteger por medio de esos recursos a la población menos favorecida, brindado con ello igualdad de oportunidades con aquellos que la poseen.

El principio de capacidad económica también debe combinarse con el principio de justicia en el gasto público, con lo que se invita a la administración a hacer un uso racionalizado del gasto, conllevando a que la administración ponga en un estado de indefensión al obligado imponiendo su poder frente a ellos. ${ }^{26}$

La capacidad contributiva se deriva de los ingresos patrimoniales percibidos ya sea mensuales, semestrales o anuales según lo imponga la obligación tributaria y estas deben provenir del ejercicio de actividades laborales o personales de los individuos. ${ }^{27}$

Según Mario Augusto Saccone, la capacidad contributiva adquiere una significación:

1) en el jurídico positivo, donde expresa que un sujeto es titular de derechos y obligaciones con arreglo a la normativa tributaria vigente, 2 ) en el ético económico, donde se designa la aptitud económica del sujeto para soportar, o ser destinatario del impuesto y 3 ) en el técnico económico, esto es, los principios, reglas, procedimientos y categorías relativas a la operatividad, o eficacia recaudatoria de los impuestos. ${ }^{28}$

II. Págs. 377-462. Tecnos. (1976). "Este principio no es conceptuado por toda la doctrina como el principal reflejo de la justicia tributaria, ni tampoco ha sido así a lo largo de la historia. Esta posición contraria ha sido mantenida".

26 Ver María del Pilar Ruiz Rescalvo. La prescripción tributaria y el delito fiscal. Pág. 57. Dikynson. (2004). "La doctrina sí ha definido el principio de capacidad contributiva como una regla cuantitativa de la posibilidad real de contribuir de cada sujeto pasivo. Lo que Sainz de Bufanda define como capacidad contributiva relativa, diferenciándola de la capacidad contributiva absoluta: "No basta, por tanto, saber que han de contribuir al levantamiento de las cargas públicas quienes tengan capacidad económica para ello (capacidad contributiva absoluta)".

27 Ver Gabriel Casado Ollero. El Principio de constitucionalidad en los impuestos indirectos I y II. Civitas. Revista Especial de Derecho Financiero. Números 33 y 34 . "Indudablemente este es uno de los principios más relevantes de los que se presiden la imposición, que ha de realizarse con un mayor o menor alcance en la mayoría de los tributos que componen nuestro sistema tributario, ya sean tasas, contribuciones especiales o impuestos, sean estos últimos directos o indirectos".

28 Ver Mario Augusto Saccone. Manual de derecho tributario. Pág. 66. La Ley. (2002).
El principio de capacidad contributiva limita de forma material el poder del Estado en cuanto al contenido general de la norma, y el principio de legalidad constituye el límite formal en cuanto a la norma.

\section{PRINCIPIO DE IRRETROACTIVIDAD TRIBUTARIA}

Un principio elemental que rige la aplicación de la ley es su irretroactividad, que significa que la ley no debe tener efectos hacia atrás en el tiempo; sus efectos sólo operan después de la fecha de su promulgación.

La Corte Constitucional ha manifestado en repetidas oportunidades que la retroactividad de la ley está íntimamente ligada con su aplicación en el tiempo, pues una ley no puede tener efectos hacia el pasado, salvo que se trate de garantizar el principio de favorabilidad, pues el legislador contempla una serie de preferencias al contribuyente.

El artículo 338 C.P. prohíbe que se aumenten las cargas al contribuyente, modificando las regulaciones en relación con periodos vencidos o en curso. La razón de esta prohibición se fundamenta en que el Estado no puede modificar la tributación con efectos retroactivos, con perjuicio de los contribuyentes de buena fe.

En diferentes oportunidades, la Corte Constitucional ha mencionado que el principio de irretroactividad constituye la premisa según la cual se prohíbe la generalidad de las circunstancias, teniendo como base el mantenimiento de la preservación del orden público con la finalidad de plasmar la seguridad y estabilidad jurídica que una ley tenga efectos con anterioridad a su vigencia.

Salvo circunstancias especiales que favorezcan tanto al destinatario de la norma como a la consecución del bien común de manera concurrente, la retroactividad debe estar plasmada bajo el principio de favorabilidad al contribuyente.

Desde los canonistas antiguos, Pedro Lombardo ha manifestado acerca del principio de retroactividad de la ley tributaria que:

[...] para que una ley fuese retroactiva, debía tener unas razones muy especiales que ameritaran tal efecto extraordinario. Los estudiosos del derecho canónico estimaban la irretroactividad como derecho divino, al paso que la retroactividad era de derecho humano. 
La irretroactividad nace en el derecho romano y se extiende luego por el mundo, convirtiéndose en un principio de aplicación de la ley aceptado universalmente; es decir, válido en todos los tiempos y en todos los lugares.

La dinámica propia del Estado por las nuevas tecnologías (TIC), el desplazamiento de la población, el sobrepoblamiento de las ciudades, obliga a modificar al legislador la normatividad en aras de lograr el interés de la colectividad en general, lo cual no pretende que un determinado régimen tributario rija al contribuyente siempre, esto es, que se convierta en inmodificable, puesto que si existen razones políticas, económicas, sociales o de conveniencia, puede entenderse la aplicación retroactiva de una ley cuando esta sea favorable al contribuyente.

En general, Arturo Valencia Zea expresa respecto del efecto retroactivo que

[...] está prohibido por razones de orden público. Las personas tienen confianza en la ley vigente, y conforme a ella celebran sus transacciones y cumplen sus deberes jurídicos. Dar efecto retroactivo a una ley equivale a destruir la confianza y seguridad que se tiene en las normas jurídicas. Además especialmente cuando se trata de la reglamentación de toda una institución jurídica, existe verdadera imposibilidad para regular el efecto retroactivo. ${ }^{29}$

\section{A. La esencia de la irretroactividad}

La esencia del principio de irretroactividad de la ley tributaria es la imposibilidad de señalar consecuencias jurídicas a actos, hechos o situaciones jurídicas que ya están formalizados jurídicamente, salvo que se prescriba un efecto más perfecto tanto para el sujeto de derecho, como para el bien común, de manera concurrente, caso en el cual la retroactividad tiene un principio de razón suficiente para operar, pues lo imperfecto siempre se sujeta a lo más perfecto, dada la naturaleza perfectible de la legalidad.

\section{B. La finalidad de la irretroactividad}

En el sentido teleológico del principio de la irretroactividad de la ley es una medida técnica escogida para dar seguridad al ordenamiento jurídico; dentro de la

29 Ver Arturo Valencia Zea. Derecho civil. Parte general y personas. Tomo I. Pág. 184. Temis. (1988). técnica jurídica es un principio de aplicación más que de interpretación previa. La interpretación y la aplicación son operaciones de tracto sucesivo.

\section{La naturaleza jurídica del principio \\ de irretroactividad}

En la generalidad de las circunstancias se prohíbe, con base en la preservación del orden público y con la finalidad de plasmar la seguridad y estabilidad jurídicas, que una ley tenga efectos con anterioridad a su vigencia, salvo circunstancias especiales que favorezcan tanto al destinatario de la norma como a la consecución del bien común, de manera concurrente. Lo anterior indica que no se trata de un principio absoluto, pues el universo jurídico no admite posiciones de tal carácter, por ser una coordinación de posibilidades racionales. La racionalidad exige, pues, antes que formas únicas e inflexibles, una sana adecuación de la forma jurídica al contenido material que se ha de ordenar.

\section{PRINCIPIO DE GENERALIDAD}

Este principio consagra que si una determinada persona se encuentra inmersa en una situación que lo obliga a contribuir, debe hacerlo sin importar la raza, sexo o religión. No se trata de obligar a todos a cancelar el tributo sino de disciplinar a aquellos que deben realizarlo y tienen la capacidad económica para hacerlo.

El límite de la generalidad está establecido por las exenciones que se hacen a un determinado grupo de la población, ya sea por su estado de vulnerabilidad o porque ellos representan un interés social y económico de la nación, como por ejemplo los centros de caridad, centro culturales, etcétera.

\section{PRINCIPIO DE NO CONFISCATORIEDAD}

El Estado protege la propiedad privada en todas sus esferas según lo contempla el artículo 58 Superior; la administración deberá exigir la cancelación de la obligación por vía directa para no violar este precepto constitucional. El valor que se debe gravar debe estar acorde con el valor real del bien, debe ser proporcional al tiempo, modo y lugar en que se encuentra. 


\section{PRINCIPIO DE ARMONIZACIÓN}

El legislador puede adoptar medidas conducentes a armonizar el principio de la unidad económica con el de la autonomía de los entes territoriales, facultad que se justifica para articular los niveles nacional y territorial, con el fin de evitar una situación de anarquía institucional.

El Estado es uno solo, sin separación tajante ni independencia entre sus niveles nacional y territorial. Precisamente es el principio de coordinación el que permite al legislador armonizar las facultades de las autoridades nacionales con las de las territoriales.

En repetidas oportunidades, la Corte ha hecho referencia a la necesidad de definir la tensión entre el principio de unidad nacional y el principio de autonomía territorial buscando principalmente la armonía. El equilibrio entre el poder central y la autonomía territorial constituye limitaciones recíprocas. Así, si la unidad nacional prevalece de conformidad con lo dispuesto en la Carta Política al establecer que la autonomía debe desarrollarse dentro de los límites previstos por la Constitución y la ley, la reglamentación debe respetar, a su vez, el contenido esencial de la autonomía territorial.

\section{Conclusiones frente al tema tratado}

Dentro de las normas tributarias colombianas se ha buscado siempre llevar un equilibrio económico y social buscando el aporte para beneficio y protección de aquellos que se encuentren en estado de vulnerabilidad. No obstante, no podemos convertir ese afán en cumplir los fines esenciales del Estado Social de Derecho en detrimento patrimonial de otros por eso es importante y necesario que los principios establecidos en la Constitución Política actúen dentro de las normas imponibles para brindar un mayor equilibrio y evitar arbitrariedades por parte de la administración.

\section{REFERENCIAS}

Alfredo Lewin Figueroa. Principios constitucionales del derecho tributario. Análisis de la jurisprudencia de la Corte Constitucional. 1992-2001. Pág. 135. Instituto Colombiano de Derecho Tributario. (2002).
Ángeles García Frías. La financiación territorial mediante recargos: un análisis jurídico. Pág. 151. Universidad de Salamanca. (1994).

Antonio Berliri. Apuntes sobre el fundamento y contenido del Art. 23 de la Constitución. Págs. 139-233. (1961).

Arturo Valencia Zea. Derecho civil. Parte general y personas. Tomo I. Pág. 184. Temis. (1988).

Carlos Palado Taboada. Apogeo y crisis del Principio de capacidad contributiva. Estudios homenaje al maestro $\mathrm{Fe}$ derico de Casto. Vol. II. Págs. 377-462. Tecnos. (1976).

Catalina García Vizcaíno. Derecho tributario, consideraciones económicas y jurídicas. Edición de Palma. (1996).

Mario Augusto Saccone. Manual de derecho tributario. Pág. 66. La Ley. (2002).

César Romero Molina. El Principio de legalidad tributaria en la expedición de normas territoriales. Revista DIXI. 2010. At. 115-121.

Corte Constitucional de Colombia. Sentencia C-445 de 1995. (M.P. Alejandro Martínez Caballero: Octubre 4 de 1995).

Corte Constitucional de Colombia. Sentencia C-419 de 1995. (M.P. Antonio Barrera Carbonell: Septiembre 21 de 1995).

Corte Constitucional de Colombia. Sentencia C-183 de 1998. (M.P. Clara Inés Vargas H: Abril 16 de 1998).

Corte Constitucional de Colombia. Sentencia C-261 del 2002 (M.P. Clara Inés Vargas Hernández: 16 de Abril del 2002).

Corte Constitucional de Colombia. Sentencia C-643 del 2002 (M.P. Jaime Córdoba Triviño: Agosto 13 del 2002).

Corte Constitucional de Colombia. Sentencia C-734 del 2002 (M.P. Manuel José Cepeda Espinoza: Septiembre 10 del 2002).

Corte Constitucional de Colombia. Sentencia C-1383 del 2003. (M.P. Clara Inés Vargas H: Abril 16 del 2003).

Corte Constitucional de Colombia. Sentencia C-664 del 2009. (M.P. Clara Inés Vargas H: Abril 16 del 2009).

Corte Constitucional de Colombia. Sentencia C-173 del 2010. (M.P. Clara Inés Vargas H: Abril 16 del 2010).

Cruz de Quiñonez 1. Lecciones de derecho tributario inspiradas por un maestro. Tomo I. Liber Amicorum en homenaje a don Eusebio González García. Pág. 162. Universidad del Rosario. (2010).

Enrique Evans de la Cuadra. Los tributos ante la Constitución. Pág. 66. Jurídica de Chile. (1997).

Gabriel Casado Ollero. El Principio de constitucionalidad en los impuestos indirectos I y II. Civitas. Revista Especial de Derecho Financiero. Números 33 y 34. Art. 187.

Hugo Mario Sierra \& Alejandro Salvador Cántaro. Lecciones de derecho penal. Parte general. Pág. 121. Universidad Nacional del Sur. (2005). 
Héctor Villegas. Curso de finanzas, derecho financiero y tributario. Pág. 190. Ediciones Depalma. (2001).

Isaac Merino Jara. Derecho financiero y tributario. Parte general. Lecciones adaptadas al EEEs. Pág. 108. Tecnos. (2011).

Juan Martín Queralt, Carmelo Lozano Serrano \& Francisco Poveda Blanco. Derecho tributario. Pág. 58. Thomson Aranzadi. (2011).

Juan Rafael Bravo Arteaga. Derecho tributario: escritos y reflexiones. Pág. 156 Universidad del Rosario. (2008).
Lejeune Valcárcel. Seis estudios de derecho constitucional e internacional tributario. Aproximación al Principio de igualdad tributaria. Pág. 121. Edersa. (1980).

Marco Antonio Méndez Moreno. Derecho financiero y tributario. Parte general. Lecciones de cátedra. Pág. 85. Lex Nova. (2008).

María del Pilar Ruiz Rescalvo. La prescripción tributaria y el delito fiscal. Pág. 57. Dikynson. (2004).

Ramón Valdés Costa. Instituciones de derecho tributario. Pág. 121. Lexis Nexis Depalma. (2004). 